\title{
Navigating Gendered Relational Spaces in Talanoa: Centring Gender in Talanoa Research Methodology
}

\author{
Moeata Keil
}

\begin{abstract}
Talanoa is a research methodology that foregrounds Pacific cultural values and acknowledges the importance of the positioning of researchers and participants in the research space. Researchers are encouraged to consider how their social characteristics, such as their gendered social positioning, shape their interactions with participants. Scholarship that carefully examines the significance of positionality, and approaches research with Pacific people from a Pacific epistemological stance, provides critical conceptual and practical guidance. In this paper, as a married Samoan mother and early career researcher in the social sciences, I reflect on gendered relational spaces in one-on-one talanoa with Pacific mothers and fathers.
\end{abstract}

\section{Introduction}

Pacific research methodologies emerged in response to the marginalisation and silencing of Pacific voices and perspectives in research. ${ }^{1}$ The advances made by feminist scholars in recognising and creating qualitative and inclusive research aided the establishment of Pacific research methodologies and emphasised the value of understanding those involved in research from within their own social, gendered, and cultural contexts. ${ }^{2}$ In the same way that feminist methodological researchers have critiqued traditionally privileged positivist research as being a highly masculinised mode of knowledge production, ${ }^{3}$ scholars such as Gegeo and WatsonGegeo argue that much research with Pacific people and cultures has been done by "outside researchers" who have their own accompanying theoretical and methodological constructs that they have used to make sense of Pacific people and cultures. ${ }^{4}$

In considering epistemology, Vaioleti argues that "[r]esearchers whose knowing is derived from Western origins are unlikely to have values and lived realities that allow understanding of issues pertaining to knowledge and ways of being that originate from [people living in] . . . Sāmoa, Tonga, Fiji, Tuvalu or the other Pacific nations." "Thus, research methodologies that were designed to identify and explore issues in a Western context are not necessarily useful for identifying issues within diverse Pacific communities and cultures. In response, Pacific scholars have created and cultivated Pacific methodological spaces that recognise the value of giving a Pacific voice to Pacific ways of seeing, knowing, being and doing. Such spaces emphasise the significance of approaching, understanding, and interpreting Pacific people's lives and experiences from within their own cultural contexts and worldviews. ${ }^{6}$

In this paper, I analytically reflect on and discuss my use of the talanoa research methodology and the accompanying method of one-on-one talanoa. Talanoa stems from Pacific oral traditions of producing, sharing and transferring knowledge through conversations and talk. ${ }^{7}$ Central to talanoa is the foregrounding of Pacific cultural values and relationality that acknowledges the significance of the positionalities of researchers and participants in shaping talanoa and the research space more generally. Current scholarship examines the significance of positionality and approaching research with Pacific people and communities from a Pacific epistemological stance, offering conceptual and practical advice and guidance on how 
researchers might navigate the vā or relational space between themselves and participants. ${ }^{8}$ As Vaioleti and others assert, Pacific participants act differently in talanoa depending on both their own and the researcher's social characteristics, including age, gender, ethnicity, cultural rank, and community standing. ${ }^{9}$ Pacific researchers are therefore encouraged to consider and be cognisant of how the social characteristics of both researchers and participants shape and impact the quality of the talanoa.

Given the significance of positionality, it is important that I situate and acknowledge my position: I am a thirty-five-year-old married Samoan woman, mother and early career researcher in the social sciences. My husband is Samoan/Māori and together we have two children, a seven-year-old son and a thirteen-year-old daughter. I was born and raised in Sāmoa, in the villages of Vaimea, Moamoa and Afiamalu, and moved to Aotearoa-New Zealand in 2003 to pursue a tertiary education. My doctoral research explored separated heterosexual Pacific parents' experiences of family life following parental separation, with ten mothers and five fathers. The mothers and fathers who participated in my research were ethnically diverse: four mothers identified as Samoan/Pālāgi, ${ }^{10}$ two as Samoan, one as Tongan, one as Cook Island Māori, one as Tongan/Māori and one as Samoan/Fijian/Māori. Of the five fathers, four identified as Samoan and one as Samoan/Pālāgi.

How researchers traverse and negotiate the gendered relational space that exists between themselves and their participants in the research space, however, is an underexplored area of research. Vaioleti argues that in Pacific cultures, to be cognisant of gendered relations, bodies, and dynamics between men and women is to be aware of the vā tapu, or the spiritually and culturally embedded sacred and often restricted relations between men and women. ${ }^{11}$ Vaioleti asserts that to do research in the relational space of vā tapu requires drawing on culturally appropriate practices and responsive interventions that mediate and in essence neutralise the relational space that exists between men and women so that they become noa or neutral, thereby enabling talanoa between men and women. ${ }^{12}$ However, there is an absence in the literature of discussion on how researchers using talanoa engage in the practice of making gendered relational interactions and spaces noa, and whether the gendered relational space can be made noa. The current scholarship suggests that the vā tapu between men and women is so absolute that it requires researchers to only engage in talanoa with those of their same gender. ${ }^{13}$ The idea is that for the researchers and participants to achieve a fruitful, engaging, meaningful, and authentic talanoa, women should talanoa with women, and men with men. The implication is that researchers should not transgress these gendered relations and dynamics in talanoa, as doing so might impact the integrity and quality of the talanoa and consequently, the data derived. Considering the nuanced and close attention that talanoa plays to positionality and Pacific research values, in this paper, I analytically reflect on how I negotiated and traversed the relational gendered space in my one-one-one talanoa with the Pacific men and women who took part in my doctoral research. The following section establishes the context of my examination by outlining talanoa as a research methodology and highlighting the absence of clarity and guidance around navigating gendered positionings, relations and spaces in talanoa.

\section{Talanoa Research Methodology}

Talanoa is an established research methodology that has been deployed in a variety of Pacific research contexts in Aotearoa-New Zealand and abroad. ${ }^{14}$ Drawing on Churchward's Tongan definition, Vaioleti describes talanoa "as a conversation, a talk, an exchange of ideas." 15 
Talanoa is formulated from two words, "tala" and "noa": "tala" which means to tell or to talk, and 'noa' which means anything or nothing in particular." 16 When combined, talanoa is to talk about anything and nothing in particular. In terms of research methods, talanoa encourages face-to-face conversations that can be between two people (for example, one-on-one talanoa) or within a group of people (for example, focus group talanoa). The nature and focus of the talanoa is determined and shaped by both the researcher and participants, and requires an understanding of the relationality and connectedness between all those involved in the research space.

As an approach to research, talanoa moves away from and challenges Western methodological approaches to research. This gives Pacific people the opportunity to relate their experiences and lived realities in their own words, and, significantly, in an environment and space that values and understands diverse Pacific cultural protocols, practices, and worldviews. ${ }^{17}$ Talanoa can be viewed as one way to integrate the diverse Pacific epistemologies and cultural principles and practices with academic knowledge production processes across the Pacific. Talanoa offers the possibility of working in culturally appropriate ways that facilitate research with diverse Pacific people and allows for a more authentic portrayal of diverse Pacific peoples' experiences than that obtained from Western research methods. ${ }^{18}$ Talanoa is, as Vaioleti notes, "a personal encounter where people story their issues, their realities and aspirations. It allows for more mo'oni (pure, real, authentic) information to be available for Pacific research." 19 Although such an approach is similar to feminist intersectional and decolonoial approaches to research and, as Vaioleti notes, narrative interviews, talanoa is founded on fostering a relational space and necessitates the cultural connectedness between researchers and participants as co-constructors of knowledge and research. ${ }^{20}$

Vaioleti lists five 'ulungaanga faka-Tonga (Tongan cultural principles) that can be applied in other contexts and are necessary for cultivating the $v \bar{a}$ or relational space between researchers and participants, and for engaging in talanoa. ${ }^{21}$ These include: faka'apa'apa (being respectful and humble); anga lelei (being generous, kind and calm); mateuteu (being well prepared, hardworking, culturally versed, professional); poto he anga (knowing what to do and doing it well); and 'ofa fe'unga (showing appropriate compassion, empathy, and love for the context). Vaioleti emphasises the centrality of these cultural principles in research protocols, which allow for a respectful and ethical engagement with and between Pacific people. ${ }^{22}$

Significantly, these cultural protocols and practices are not simply superficial cultural rituals. Rather, they are central to ensuring research quality. To elaborate, the depth and quality of the data gathered from the research is highly dependent on the relationship between the researcher and participants. ${ }^{23}$ Adhering to cultural protocols within talanoa strengthens the relationship between the researcher and participant, and consequently the quality of the data derived from the talanoa. Without these values at the core of research design and implementation, researchers risk engaging in a talanoa that is characterised by the researcher asking questions and participants providing short and simple responses, or the talanoa being short in duration, or the participant withdrawing from the study altogether. ${ }^{24}$ However, once the relationship between the researcher and participant has been developed, quality will be added to the research in terms of the participant wanting to have an in-depth talanoa and, reciprocally, the researcher not wanting to let down participants with whom they have developed a relationship. Thus, when 
doing talanoa, an "ethic of care" is required that acknowledges researchers and participants as co-constructors of knowledge, and that demonstrates respect for participants' time and talk. ${ }^{25}$

The literature on talanoa, however, is silent on how researchers using talanoa might traverse gendered relational spaces. Questions remain about how researchers might draw on culturally appropriate and responsive principles and practices that enable them to cultivate the vā, including vā tapu (or relational space, including, the gendered relational space) between researchers and participants, or how researchers can cultivate connectedness across transversals of gendered sociocultural positionings and spaces. The following section begins with a discussion of the ways I cultivated and navigated the vā (relational space) with the men and women in my research, before moving on to discuss the differential and gendered approaches I took with Pacific mothers and fathers. The forthcoming sections also demonstrate the overlapping nature and dimensions of methodology and method, where the philosophical underpinnings of why we do what we do in research shapes how and what we do in research.

\section{Cultivating the Vā (Relational Space)}

Fostering the relational space and enacting an ethic of care meant recognising that although participants had volunteered to take part in my research, I could not go into the talanoa expecting participants to simply respond to my questions. Practicing and understanding the notion of mateuteu (being culturally versed) and pote he anga (knowing what to do and doing it well) meant understanding that finding out about participants' lived experiences, and engaging in a genuine talanoa, hinged on my willingness to invest my personal identity. ${ }^{26} \mathrm{By}$ investing one's personal identity, experience and biography in the relationship (rather than expecting participants to share their lives, stories and experiences), researchers and participants are able to build rapport with one another, ${ }^{27}$ thus creating a relationship of trust and reciprocity that encourages an openness to talanoa. ${ }^{28}$ In doing so, the talanoa can be conducted as more of a free-flowing conversation as opposed to a "question and answer" mode of talking, with the burden of talanoa laid on participants.

In an effort to build rapport as well as create a sense of affinity and connectedness that acknowledges and cultivates the vā (relational space) between us, we spent time talking about our experiences prior to asking any research-related questions. Because I am Samoan and all the participants were of a Pacific ethnicity, we usually started our talanoa by talking about our island heritage. For example, where we came from in the Pacific and what brought us to Aotearoa-New Zealand. I told them about my children and shared some of my parenting experiences, challenges and aspirations. Given that my research explored separated heterosexual Pacific mothers' and fathers' experiences of post-separation familial life and that I was interested in their parenting experiences, I felt that it was important that I shared with them stories about my children. I felt that this was important to create a level of trust between us and also because it conveyed to them that our talanoa was a safe space to disclose intimate details and stories about our family lives. Moreover, the reciprocal sharing cultivated a relationship of reciprocity that worked towards minimising any power imbalances and extractive interview processes, and ensured that we both left the talanoa with a feeling of knowing one another and each other's lives. Doing so fostered a sense of connectedness that showed respect for the relationship and vā (relational space) that existed between us, and also established a level of trust in how I would use the insights gained from our talanoa. 
As Vaioleti asserts, talanoa is guided by the "cultural operationalization of appropriate ethics" that emerge from, and are informed by, diverse Pacific worldviews. ${ }^{29}$ Part of this cultural operationalisation of appropriate ethics meant being cognisant of the role that status plays in structuring social interactions between Pacific peoples. My own experiences, tacit knowledge, and cultural competency involved recognising social and cultural rank and status that is often marked in Pacific cultures by age and generation. However, because I was of similar age to my participants, there were no generational gaps between us (for example, none of the participants were grandparents or elders in the community), and our talanoa was able to flow more easily (or less inhibited by age and generational barriers).

Being a Samoan mother doing research with Pacific parents in many ways made me somewhat of an "insider" in this research. ${ }^{30} \mathrm{I}$ was an insider because we shared tacit understandings, experiences, and knowledge of being "Pacific" and also of having children, and thus, being parents. Below is a brief excerpt from one of the mothers that illustrates this tacit knowing derived from being a mother:

Moeata: Can you tell me about your evening routines, like from when you get home from work or school to when the kids go to bed?

Salote $^{31}$. . . . oh, trying to get the kids into bed is so much fun [both laugh]

This short excerpt illustrates how, without saying much, this mother knows that I understand that she is not being literal about bedtime routines being "fun," because I have children myself. Rather, she conveyed through one word - "fun" - the daily struggle of trying to coax children to bed and keep them there. She later said:

Salote: . . . I start our bedtime routine at around 7pm, but they're probably not in bed and asleep until just before 9pm. ... [They're] always trying to find ways and reasons to not go to bed . . . you know, "I'm hungry. I need to pee." Can I have a this or a that. ... Oh, you know their lists go on and on.

Moeata: Ah yes, I do, my kids are exactly the same.

Salote: Parenting is so much fun [both laugh].

However, this tacit knowing was also derived from having similar Pacific cultural values, understandings, and experiences. There was a felt knowing, sharing, and understanding of each other's worldviews, meanings, and experiences. To give you an example from one of the fathers in my study:

Moeata: How important is it to you for your children to spend time with their extended family on both sides?

Tavita: Well, that's a question ... I don't think I've thought about it like that. Yeah, important, but you know Island families, do they have a choice? [both laugh]. . . . There's always something going on in the family, you know what it's like, fa'alavelave $i$ ' $\overline{1}$, fa'alavelave i 'o [important family/cultural events here, important family/cultural events there].

This father, like most other participants, recognised and acknowledged that I could relate to his own experiences of doing family in Pacific cultures, and he demonstrates this by saying, "you know what it's like." In the excerpts shared above, laughter was not so much about humour, but rather a way of showing and reaffirming shared understandings and experiences. As such, laughing, and more importantly, laughing at the right moment, demonstrated and conveyed a 
level of shared knowing and understanding of each other's experiences and thus fostered the relational space between us. However, how this relational space was traversed changed depending on whether I was in talanoa with men or women. The discussion that follows explores how I navigated the gendered relational space in my talanoa with men and women.

\section{Navigating the Gendered Vā (Relational Space)}

In an effort to build "culturally appropriate and respectful relationships" with participants, I approached and conducted my talanoa with the men in my study differently from my talanoa with the women. ${ }^{32}$ The "cultural operationalization of appropriate ethics" in my research involved an awareness and acknowledgment of the role of gender in structuring and shaping my interactions and talanoa with participants, particularly with the men in my study. ${ }^{33}$ In the sections below, I share my experiences and reflections as well as anxieties over how I navigated these gendered relational spaces, revealing the importance of having delicate cultural knowledge and engaging in reflexive research praxis. ${ }^{34}$ As previously discussed, the social characteristics of the researcher and participant shapes and impacts the quality of the talanoa, including how the talanoa is organised and approached.

With the women in my study, the date, time, and physical location of our talanoa was arranged according to their preferences. We met at a range of different times and places that best suited them, including evenings in their homes, places of work, cafés, and public playgrounds. Some of the women brought their children, while others did not. I chatted and played with their children, and on a few occasions, I watched their children while they stepped away to the restroom or to retrieve something from another room. We built rapport almost effortlessly; it happened organically through our reciprocal sharing of our life stories and journeys. There were so many points of identification and sameness based on sharing a similar ethnic and gendered identity, being similar in age and being mothers. As a result, I was aware of the gendered dynamics at play - there were none that transgressed sociocultural norms, values, and expectations - because our interaction and the vā (relational space) between us was noa.

To put it another way, there were no cultural restrictions or prescriptions on how we should navigate the gendered space between us. The gendered interaction and relationship was not inhibited by vā tapu as it was already defaulted as noa. As such, the cultural principles that Vaioleti asserts are necessary for cultivating the vā (relational space) and engaging in talanoa were mobilised almost non-reflexively and derived from tacit knowing, having, and sharing Pacific cultural values and ways of moving and being gendered in the world. ${ }^{35}$ As a result, our talanoa flowed as a talanoa between friends, where once rapport was built, we talked, shared, laughed, and often cried together.

Although I shared similar cultural values, understandings and experiences of being Pacific and a parent with the men in my study, I understood that I could not approach the talanoa with the men in the same way that I did with the women. For this reason, when it came time to arrange a day, time, and location to meet, I could not approach it open-endedly like I did with women. With the men, to demonstrate care, respect, and to safeguard the relational gendered space between us (so as to not assume that their voluntary participation created a noa gendered relational space), I initiated our exchanges about meeting by suggesting that we meet at a café in an area that was convenient for them, or at their or my place of work. I did this to avoid an invitation of meeting at their home or some other private space and also to quell any possible 
weariness on their part, as well as my own anxiety, about engaging in a woman-and-man talanoa.

Worthy of highlighting is that my anxiety was not derived from a fear over my physical safety (as my participants were not known to me); it was more a desire to ensure that we did not meet and talanoa in a private space that might create too intimate an environment between me and the men in my research. The invitation to meet, and consequently meeting in a public space, operated as a means through which I exercised poto he anga (knowing what to do and doing it well). In this context, it meant knowing what to do to acknowledge and maintain the vā tapu that conditioned our interactions and existed between us in the gendered relational space and relationship of feagaiga or the sacred covenant articulated as a respectful bond and distance between a brother and sister, informing gendered relations between men and women in Samoan contexts and cultures. This was particularly important given that all of the men in my study were also Samoan.

To manage the woman-to-man gendered dynamics and gendered relational space in our talanoa, it was important that I set the tone of, and context for, the meeting and our one-on-one talanoa. Part of how I did this was by making sure that I arrived 20 minutes early to our talanoa and that I had the necessary research items visible on the table in front of me, such as the participant information sheet, consent form, pen, and paper. Although I was bound by formal university ethics requirements to present and discuss these items with participants, they were also used as props that facilitated context for our talanoa. Fa'avae et al, however, notes how such documents and forms operate as a hindrance to building relationships and engaging in talanoa with the Tongan men who participated in their study, a sentiment that I also found to be true in my talanoa with the women in my study. ${ }^{36}$ The commonality between the experiences of Fa'avae et al. and my own was that in these instances (where research documents hindered talanoa), we were in talanoa with participants of the same gender as the researcher. However, demonstrating poto he anga (knowing what to do) in the gendered relational space and a relationship of feagaiga meant recognising that what worked with the women in my study (and the men in the study by Fa'avae et al.) could not form the basis of the approach I undertook with the men in my study (or in woman-to-man talanoa). Thus, for the men and I to engage in a talanoa and respectfully navigate the vā tapu, the research context could not be removed from our interactions, nor could the relationship be made noa. Rather, our interactions needed to be focused and oriented around the research.

As I discussed earlier, with the women in my study, once we established a rapport, the research context of our talanoa seemed to disappear and we could freely and openly engage in talanoa as friends. When I presented the participant information sheet and the consent form, the women were largely uninterested in the documents and more interested in getting to know me, as a Samoan/Pacific woman and mother and then as a Samoan/Pacific researcher. The men, however, closely examined the participant information sheet and the consent form. Unlike with women, the rapport building in my talanoa with men focused on me as a Samoan/Pacific researcher and the research project more generally, and then as a Pacific person who was born and raised in Sāmoa. On reflection, when I think about the different ways that the women and men and I built rapport and trust, even in terms of how they engaged with the participant information sheet and the consent form, I realise that it was not just me reflexively managing the gendered relational space and vā tapu with the men in my study. Rather, the men in my 
study were also actively engaged in managing the gendered relational space and safeguarding our relationship of feagaiga. Thus, the men and I were both enacting and practicing mateuteu of being well prepared, culturally versed and professional and poto he anga (knowing what to do and doing it well). In particular, focusing on the research context for me, and I imagine for the men in my study too, operated as a form of boundary construction and maintenance work, or relational work, that cemented the context for our meeting, interaction and talk, thereby enabling our talanoa to proceed.

Further, managing the gendered relational space and demonstrating poto he anga meant managing my physical appearance and gendered body. I ensured that I presented myself in culturally appropriate gendered ways by dressing conservatively and professionally, not wearing make-up and having my hair tied in a bun. I also had to manage the extent to which I demonstrated 'ofa fe'unga of showing appropriate compassion, empathy and love and anga lelei (being generous and kind) in our talanoa. I was constantly reflecting throughout our talanoa on how my words, questions, emotions and actions might be conveyed, interpreted or misinterpreted. For example, when the women in my study showed emotions and feelings of pain, sadness, hurt or shame, I showed compassion, empathy and love for the situation by reassuring them with words, touching their arm or holding their hand. However, with the men in my study, in similar situations, I could not demonstrate the same level of compassion or empathy, nor could I close the physical space between us. Instead, I offered words or expressions of empathy and compassion for the context. Part of practicing mateuteu, of being culturally versed in these instances, meant reflexively and continuously being aware of and managing the gendered relational dynamics in culturally appropriate and respectful ways.

Although I wanted to build a rapport that enabled a good conversation with the men in my study, I did not and could not build too much rapport or too strong of a sense of familiarity that removed the research context from our interaction. Instead, the research context needed to remain in focus as it created the context for our interaction and talanoa. Thinking about how I consciously and reflexively navigated the gendered relational space that existed between me and the men in my study, this meant towing a line between relationship building and boundary maintenance. Drawing on Iosefa and Aiga Ethics Komiti's tapasā mo aiga, or family compass framework for doing research, my talanoa with men drew on Samoan principles of soalaupule that works towards empowering equitable dialogue between people, and fealoaloa'i by ensuring that dignified boundaries were maintained to protect and safeguard the vā tapu and the integrity of our talanoa. ${ }^{37}$

Vaioleti suggests that for talanoa between men and women to occur the relational space and vā tapu must be made noa (neutral). ${ }^{38}$ In my research context, however, part of enacting mateuteu and poto he anga meant ensuring the reverse: taking precautions to not make noa or neutralise the gendered relational space between myself and the men in my study. In an effort to engage in a fruitful and respectful talanoa with the men in my study, it meant engaging in a talanoa that remained in, and maintained, the space of vā tapu. As such, it was about ensuring that I was always aware, cognisant of, and responsive to, the gendered relational space between us. Put differently, to engage in a culturally appropriate and responsive talanoa between women and men meant interacting in the relational vā tapu space. 
Approaching and conducting the talanoa with men differently from how I did with women did not diminish the overall quality of the data derived from my talanoa with men. I imagine that the men who took part in my research had many reservations about partaking in my research and doing talanoa with a woman researcher, which might have been why none of them objected to meeting in a public space or suggested an alternative location. It is my hope that I demonstrated throughout the talanoa, particularly for the men in my study, the principle of faka'apa'apa or respect for the relationship and created, in a culturally appropriate way, a space for men to share their stories and engage in research. The fact that these men opted to participate in my research and that we were able to engage in a talanoa that covered a range of issues related to post-separation family life, even if it was not as emotionally laden as it was with women, demonstrates that researchers can cultivate connectedness across transversals of gendered sociocultural positionings and spaces, and thus traverse gendered relational spaces in talanoa.

\section{Concluding Comments}

In this paper, I work through questions about how and whether Pacific researchers can genuinely and meaningfully engage in a "woman-to-man" talanoa, while still adhering to and being guided by cultural principles, protocols and practices. While undertaking my doctoral research (with woman-to-woman and woman-to-man talanoa), I often questioned whether I was authentically engaging in talanoa, or whether my research could be genuinely considered talanoa because I transgressed the gendered relational space through my talanoa with men. I sought advice and guidance from the literature, but the issue of gender was largely sidelined and cautioned as being in the realm of vā tapu.

I sought counsel from my aiga (family), particularly my mother and older brothers, and they offered advice and encouraged me, as a tama'ita'i Sāmoa (daughter of Sāmoa) working in academia, to be confident in my aganu'u Sāmoa (Samoan culture) to be able to know and discern the appropriate actions, timings and cues of the talanoa and how it should be conducted in the research space. This paper offers insights into how Pacific women and researchers, while being guided by cultural principles and engaging in reflexive research praxis, can navigate and negotiate the gendered relational space while employing talanoa as a research methodology and method. It is both a response to, and echo of, the sentiments of $\mathrm{Fa}^{\text {' }}$ avae et al., of hoping to "raise questions for conversation about the complexities of putting talanoa into research practice." 39 It also speaks to the call made by Suaali'i-Sauni and Fuli-Aiolupotea for Pacific researchers to "talk and write explicitly about their experiences" in an effort to further sharpen talanoa as research methodology and method. ${ }^{40}$ My experiences and reflections, as well as my anxieties as a budding researcher, demonstrates the need for more research that focuses on gendered social relations in the research space. This article carefully examines and documents my experiences as a way to show how researchers and participants can traverse the gendered relational space between men and women in culturally appropriate and responsive ways.

\footnotetext{
${ }^{1}$ See Melani Anae, "Pacific Research Methodologies and Relational Ethics," in Oxford Research Encyclopedia of Education, ed. George Noblit (Oxford: Oxford University Press, 2019); Elise Huffer and Ropate Qalo, "Have We Been Thinking Upside-down? The Contemporary Emergence of Pacific Theoretical Thought," Contemporary Pacific 16, no. 1 (2004): 87-116; Tamasailau Suaalii-Sauni and Saunimaa Fulu-Aiolupotea, "Decolonising Pacific Research, Building Pacific Research Communities
} 
and Developing Pacific Research Tools: The Case of the Talanoa and the Faafaletui in Samoa," Asia Pacific Viewpoint 55, no. 3 (2014): 331-44; Timote Vaioleti, "Talanoa Research Methodology: A Developing Position on Pacific Research," Waikato Journal of Education 12 (2006): 21-34; and Timote Vaioleti, "Talanoa: Differentiating the Talanoa Research Methodology from Phenomenology, Narrative, Kaupapa Māori and Feminist Methodologies,” Te Reo 56-57 (2013): 191-212.

${ }^{2}$ Vaioleti, "Talanoa: Differentiating the Talanoa Research Methodology."

${ }^{3}$ See Patricia Collins, Black Feminist Thought: Knowledge, Consciousness, and the Politics of Empowerment (New York: Routledge, 2000); Patricia Collins, "Black Feminist Thought as Oppositional Knowledge," Departures in Critical Qualitative Research 5, no. 3 (2016): 133-44; Sharlene Hesse Biber, "Feminist Research: Exploring, Interrogating, and Transforming the Interconnections of Epistemology, Methodology, and Method," in Handbook of Feminist Research: Theory and Praxis, ed. Sharlene Hesse Biber (Thousand Oaks: SAGE Publications, 2012) , 2-26; and Andrea Doucet and Natasha Mauthner, "Feminist Methodologies and Epistemology" in Twenty-first Century Sociology, ed. Clifton D. Bryant and Dennis L. Peck (Thousand Oaks: Sage Publications, 2007), 211-36.

${ }^{4}$ David Gegeo and Karen Watson-Gegeo, “'How We Know': Kwara'ae Rural Villagers Doing Indigenous Epistemology," The Contemporary Pacific 13, no. 1 (2001): 58.

${ }^{5}$ Vaioleti, "Talanoa Research Methodology," 22.

${ }^{6}$ See Huffer and Qalo, "Have We Been Thinking Upside-down?"; Suaalii-Sauni and Fulu-Aiolupotea, "Decolonising Pacific Research"; Vaioleti, "Talanoa Research Methodology"; Vaioleti, "Talanoa: Differentiating the Talanoa Research Methodology"; and Timote Vaioleti, "Talanoa, Manulua and Founga Ako: Frameworks for Using Enduring Tongan Educational Ideas for Education in Aotearoa New Zealand" (PhD thesis, University of Waikato, 2011).

${ }^{7}$ See Semisi Prescott, "Using Talanoa in Pacific Business Research in New Zealand: Experiences with Tongan Entrepreneurs," AlterNative: An International Journal of Indigenous Peoples 4, no. 1 (2008): 127-48; Vaioleti, "Talanoa Research Methodology"; Vaioleti, "Talanoa: Differentiating the Talanoa Research Methodology."

${ }^{8}$ David Fa'avae, Alison Jones and Linitā Manu'atu, "Talanoa'i 'a e Talanoa - Talking about Talanoa: Some Dilemmas of a Novice Researcher," AlterNative: An International Journal of Indigenous

Peoples 12, no. 2 (2016): 138-50; Mo'ale 'Otunuku, "Talanoa: How Can It Be Used Effectively as an Indigenous Research Methodology with Tongan People?" Pacific-Asian Education Journal 23, no. 2 (2011): 43-52; Vaioleti, "Talanoa Research Methodology"; Vaioleti, "Talanoa: Differentiating the Talanoa Research Methodology"; and Vaioleti, "Talanoa, Manulua and Founga Ako."

${ }^{9}$ See Vaioleti, "Talanoa Research Methodology"; Fa'avae, Jones and Manu'atu, "Talanoa'i 'a e Talanoa"; 'Otunuku, "Talanoa."

${ }^{10}$ Pălāgi is a Samoan term used to describe a person of typically European descent. Although originating from Sāmoa, it has gained widespread use across the Pacific, including in Aotearoa-New Zealand. A Samoan term is being used here and in other places, because the mothers and fathers who participated in my study themselves used this word to describe their European ancestry.

${ }^{11}$ Vaioleti, "Talanoa: Differentiating the Talanoa Research Methodology." In this paper, the terms and phrases Pacific, Pacific people and Pacific cultures are not intended to imply homogeneity between different Island nations, people or cultures (Anae et al., 2001). Instead, it acknowledges shared geography and shared aspects of cultural norms and practices, while still signifying the diversity and heterogeneity in people, culture and language (Koloto and Kataonga, 2007).

${ }^{12}$ Vaioleti, "Talanoa: Differentiating the Talanoa Research Methodology," 196.

${ }^{13}$ Fa'avae, Jones and Manu'atu, "Talanoa'i 'a e Talanoa"; 'Otunuku, "Talanoa"; Vaioleti, "Talanoa: Differentiating the Talanoa Research Methodology."

${ }^{14} \mathrm{Fa}^{\prime}$ avae, Jones and Manu'atu, "Talanoa'i 'a e Talanoa"; Prescott, "Using Talanoa in Pacific

Business Research"; Suaalii-Sauni and Fulu-Aiolupotea, "Decolonising Pacific Research."

${ }^{15}$ Vaioleti, "Talanoa: Differentiating the Talanoa Research Methodology," 192.

16 'Otunuku, "Talanoa," 45. 
${ }^{17}$ Setsuo Otsuka, "Talanoa Research: Culturally Appropriate Research Design in Fiji," Proceedings of the Australian Association for Research in Education (AARE) International Education Research Conference: Creative Dissent-Constructive Solutions (Melbourne, VIC: AARE, 2006), https://www.aare.edu.au/data/publications/2005/ots05506.pdf; Vaioleti, "Talanoa: Differentiating the Talanoa Research Methodology."

${ }^{18}$ Prescott, "Using Talanoa in Pacific Business Research"; Suaalii-Sauni and Fulu-Aiolupotea, "Decolonising Pacific Research"; Vaioleti, "Talanoa: Differentiating the Talanoa Research Methodology," 192.

${ }^{19}$ Vaioleti, "Talanoa Research Methodology," 30-31.

${ }^{20}$ Kimberlé Crenshaw, "Demarginalizing the Intersection of Race and Sex: A Black Feminist Critique of Anti-discrimination Doctrine, Feminist Theory and Anti-racist Politics," University of Chicago Legal Forum 1, no. 8 (1989): 139-67; Collins, Black Feminist Thought; Collins, "Black Feminist Thought as Oppositional Knowledge"; Marìa Lugones, "Toward a Decolonial Feminism," Hypatia 25, no. 4 (2010): 742-59: Vaioleti, "Talanoa: Differentiating the Talanoa Research Methodology," 192.

${ }^{21}$ Vaioleti, "Talanoa Research Methodology," 30-31.

${ }^{22}$ Vaioleti, "Talanoa Research Methodology"; Vaioleti, "Talanoa: Differentiating the Talanoa Research Methodology."

${ }^{23}$ Suaalii-Sauni and Fulu-Aiolupotea, "Decolonising Pacific Research."

${ }^{24}$ Vaioleti, "Talanoa: Differentiating the Talanoa Research Methodology," 192.

${ }^{25}$ Alexandra Allan, "Feminist Perspectives on Qualitative Educational Research," in Handbook of Qualitative Research in Education, ed. Sara Delamont (Cheltenham: Edward Elgar, 2012), 92-116; Okusitino Māhina, "Tā, Vā, and Moana: Temporality, Spatiality, and Indigeneity," Pacific Studies 33, no. 2/3 (2010): 168-202; Suaalii-Sauni and Fulu-Aiolupotea, "Decolonising Pacific Research"; Arcia Tecun, 'Inoke Hafoka, Lavinia 'Ulu' ave and Moana 'Ulu'ave-Hafoka, "Talanoa: Tongan Epistemology and Indigenous Research Method," AlterNative: An International Journal of Indigenous Peoples 14, no. 2 (2018): 156-63.

${ }^{26}$ Tēvita O. Ka'ili, "Tauhi Vā: Nurturing Tongan Sociospatial Ties in Maui and Beyond," Contemporary Pacific 17, no. 1 (2005): 83-114.

${ }^{27}$ Jo Fletcher et al., "Pasifika Students: Teachers and Parents Voice Their Perceptions of What Provides Supports and Barriers to Pasifika Students' Achievement in Literacy and Learning," Teaching and Teacher Education 25, no. 1 (2009): 24-33.

${ }^{28}$ David Fa'avae, "Negotiating the Vā: The Self in Relation to Others and Navigating the Multiple Spaces as a New Zealand-raised Tongan Male," in Questions of Culture in Autoethnography, ed. Phiona Stanley and Greg Vass (Abington: Routledge, 2018), 57-68.

${ }^{29}$ Vaioleti, "Talanoa: Differentiating the Talanoa Research Methodology," 208.

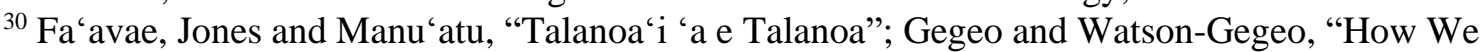
Know."

${ }^{31}$ All names shared are participant pseudonyms.

${ }^{32}$ Suaalii-Sauni and Fulu-Aiolupotea, "Decolonising Pacific Research," 335.

${ }^{33}$ Vaioleti, "Talanoa: Differentiating the Talanoa Research Methodology," 208.

${ }^{34}$ Suaalii-Sauni and Fulu-Aiolupotea, "Decolonising Pacific Research."

${ }^{35}$ Vaioleti, "Talanoa Research Methodology."

${ }^{36} \mathrm{Fa}$ 'avae, Jones and Manu'atu, "Talanoa'i 'a e Talanoa."

${ }^{37}$ Fetaui Iosefa and Aiga Ethics Komiti, "Wayfinding with Aiga (Family): Aigia Saili Manuia: Family in (Re)search of Peace," in Wayfinding and Critical Ethnography, ed. Fetaui Iosefa (New York:

Routledge, 2021), 38-52.

${ }^{38}$ Vaioleti, "Talanoa: Differentiating the Talanoa Research Methodology."

${ }^{39} \mathrm{Fa}$ 'avae, Jones and Manu'atu, "Talanoa'i 'a e Talanoa," 147.

${ }^{40}$ Suaalii-Sauni and Fulu-Aiolupotea, "Decolonising Pacific Research," 335. 